\title{
CONFERÊNCIAS NACIONAIS DE POLÍTICAS PARA A MULHER E A FORMULAÇÃO DE DIRETRIZES PARA AS POLÍTICAS PÚBLICAS DE ENFRENTAMENTO À VIOLÊNCIA CONTRA A MULHER NO BRASIL: PARTICIPAÇÃO E REPRESENTAÇÃO
}

\begin{abstract}
Maria Carolina Carvalho Motta ${ }^{1}$
RESUMO: O objetivo do presente artigo é compreender as Conferências Nacionais de Políticas para a Mulher como representação e participação popular na construção das políticas públicas de combate à violência contra a mulher no Brasil. Assim descreve o percurso institucional das instâncias protetoras dos direitos da mulher na política brasileira e a simbiose entre as conferências nacionais e as políticas públicas de inclusão no país. $\mathrm{O}$ trabalho foi estruturado a fim de analisar o conteúdo dos documentos oficiais de políticas públicas e confrontá-los com a teoria argumentativa de Habermas (2012) e com a teoria da justiça de Frazer (2013).

PALAVRAS-CHAVE: Representação, Participação e Conferências Nacionais

\section{NATIONAL POLICIES FOR WOMEN CONFERENCES AND THE CONSTRUCCION OF GUIDELINES PUBLIC POLICIES FOR COPING VIOLENCE TO WOMAN IN BRRASIL: PARTICIPATION AND REPRESENTATION}

ABSTRACT: The target of this paper is to comprehend the national conferences for women as popular representation and participation as means of constructing public policies against violence to women in Brazil. It describes the institutional protecting levels path of women rights in brasilian politics in the country. This job has been structured with the purpose of analising the contentes of public policies oficial documents and confront them to Habermas argumentation theory (2012) and Fraze's theory of justice (2013).
\end{abstract}

KEY-WORDS: Representation, Participation e National Conferences

\section{INTRODUÇÃO}

A maior crítica que se tem ao constitucionalismo latino americano está no fato de, embora suas Constituições apresentem textos fortes quanto aos direitos sociais, econômicos e culturais, a organização dos poderes permanece intocada com um modelo concentrador de autoridade. Autores como o argentino Gargarella (2016) denominam este fenômeno de modelo hiper-presidencialista sem o empoderamento popular. Segundo esta concepção os direitos constitucionalmente consagrados se tornam vulneráveis, visto que não há suporte para

\footnotetext{
${ }^{1}$ Professora Doutora da Faculdade de Direito da Universidade Federal de Goiás/Regional Goiás CONPEDI LAW REVIEW | QUITO - EQUADOR | v. 4 | n. 2 | p. 37 - 55 | JUL - DEZ | 2018
} 
concretizá-los. A concentração da instância política-decisória nestes termos, inviabiliza a participação de grupos socialmente minoritários no processo de construção da cidadania.

Neste sentido, a perversidade do sistema está em negar o reconhecimento destes grupos na distribuição de justiça. É por este motivo que Habermas (2012) acredita no agir comunicativo para a construção da democracia deliberativa e, por sua vez, Frazer (2013) afirma haver nestes modelos uma falsa representação que nega aos grupos socialmente minoritários através de regras decisórias a real participação na distribuição de justiça. Trata-se de negar-lhes a dimensão política da representação ou mesmo de estreitá-la através apenas da representação eleitoral.

Por esta razão o presente artigo apresenta uma alternativa a este modelo democrático que concentra o poder de decisão em instâncias governamentais não inclusivas. A participação e a representação de grupos minoritários ganha novos contornos com a inclusão na pauta política brasileira das Conferências Nacionais. Estes eventos, precedidos de outros de caráter local e regional, conferem a característica de participação na tentativa de resolução de problemas públicos envolvendo o próprio grupo alvo. São espaços deliberativos que permitem o debate de soluções a curto ou longo prazos pelos grupos socialmente excluídos. A par deste modelo ter abarcado mais de 80 Conferências Nacionais depois da promulgação da Constituição de 1988, aqui a discussão perpassará somente pela experiência das Conferências Nacionais de Políticas para Mulheres na construção de políticas públicas de enfrentamento à violência contra a mulher.

A experiência das Conferências Nacionais de Políticas para a Mulher gerou no Brasil três grandes propostas de políticas públicas e possibilitou um dos maiores avanços em termos de arranjo federativo para que tanto os governos locais e regionais pudessem se organizar politicamente, inclusive com pauta orçamentária, no combate à violência contra a mulher. Mérito da organização da sociedade civil conjugada com a institucionalização de instâncias governamentais inclusivas como é o caso do Conselho Nacional de Direitos das Mulheres e da Secretaria de Políticas da Mulher.

Assim, o objetivo primordial deste texto é compreender as Conferências Nacionais de Políticas para a Mulher como representação e participação popular na construção das políticas públicas de combate à violência contra a mulher no Brasil. Para tanto será necessário descrever o percurso institucional das instâncias protetoras dos direitos da mulher na política brasileira, bem como conhecer a simbiose entre as conferências nacionais e a construção das políticas públicas de inclusão no país. 


\section{CONFERÊNCIAS NACIONAIS DE POLÍTICAS PARA A MULHER E A \\ FORMULAĈ̃O DE DIRETRIZES PARA AS POLÍTICAS PÚBLICAS DE ENFRENTAMENTO À VIOLÊNCIA CONTRA A MULHER NO BRASIL: PARTICIPAÇ̃̃O \\ E REPRESENTAÇÃO}

O trabalho foi estruturado através da metodologia de pesquisa de coleta de dados oficiais, que utilizou a técnica análise de conteúdo, conjugada com levantamento bibliográfico sobre o tema participação e democracia. A partir desta proposta foi possível analisar o conteúdo dos documentos oficiais de políticas públicas publicados pelo governo federal brasileiro, além de pesquisas dissertativas desenvolvidas nesta área e confrontá-los com as teorias escolhidas.

1. INSTÂNCIAS GOVERNAMENTAIS INCLUSIVAS: O CONSELHO NACIONAL DE DIREITOS DA MULHER E A SECRETARIA NACIONAL DE POLÍTICAS PARA MULHERES

Como não podia deixar de ser, a inserção dos direitos das mulheres na agenda política do Brasil se inicia no processo de redemocratização, após 1984. O momento era de reconciliação entre Estado e sociedade e, portanto, a inclusão da pauta das mulheres era necessária à consolidação democrática. Em 1985 é criado, então, o Conselho Nacional dos Direitos das Mulheres ${ }^{2}$ ligado ao Ministério da Justiça com o objetivo de promover a liberdade, a igualdade de direitos e a plena participação das mulheres em âmbito nacional. Junto com ele também foi criado o Fundo de Desenvolvimento da Mulher ${ }^{3}$ que assegurava condições de operacionalidade ao Conselho.

Após a fase de euforia inicial, marcada pelo reconhecimento dos direitos das mulheres na constituinte de 1988 com algumas vitórias ${ }^{4}$, ocorreram alguns embates do Conselho com o próprio governo no que tange a temas ainda tidos como polêmicos: violência, racismo e direitos reprodutivos. De maneira que em 1989, sob a alegação de que já havia atingido as metas desejadas e que era necessário "enxugar" o pessoal, o conselho foi transformado em um órgão deliberativo ${ }^{5}$. A desestabilização do Conselho foi notória na vida política brasileira a partir de então.

Os anos 90 surgem para o Brasil com políticas neoliberais convivendo com as conferências internacionais sobre os direitos das mulheres. Em meio à falta de respaldo político e orçamentário, o Conselho recebe a incumbência de preparar o governo brasileiro para a participação em eventos internacionais referentes ao tema. Inclusive, em 1994, o Brasil

\footnotetext{
${ }^{2}$ Lei Federal 7353/85

${ }^{3}$ Extinto no governo Collor

4 ver Tese de Doutorado do departamento de História da UNB de autoria de Fabrícia Faleiros Pimenta intitulada "Políticas Feministas e os Feminismos na Política: O Conselho Nacional dos Direitos da Mulher (1985-2005)" defendida em 2010.

5 fase denominada de engessamento das políticas feministas por Fabrícia Faleiros Pimenta.
}

CONPEDI LAW REVIEW | QUITO - EQUADOR | v. 4 | n. 2 | p. 37 - 55 | JUL - DEZ | 2018 
é sede da Assembleia Geral da OEA que aprova a Convenção Belém do Pará, ícone no combate à violência contra a mulher no sistema regional de direitos humanos. Há, portanto, uma retomada institucional com a inclusão do Programa Nacional de Combate à Violência Doméstica e Sexual no $1^{\circ}$. Plano Nacional de Direitos Humanos em $1996^{6}$.

Em 2002, já no final do governo Fernando Henrique Cardoso, ocorre a criação da Secretaria dos Direitos da Mulher, com status de Ministério ${ }^{7}$. A intenção era retomar um espaço legítimo de formulação de políticas públicas para a mulher. Em 2003, com a entrada do governo Lula, a denominação passa a ser Secretaria Especial de Políticas para as Mulheres e o Conselho dos Direitos das Mulheres, composto por representantes do governo e da sociedade civil, passa a ser órgão consultivo. O salto qualitativo na implementação das políticas públicas ocorre em 2009 com a liberdade orçamentária e com a autonomia para as políticas públicas alcançadas ${ }^{8}$. Em 2015, há a fusão de três secretarias com a criação do Ministério das Mulheres, da Igualdade Racial e dos Direitos Humanos. No entanto, o governo Dilma é interrompido por um processo de Impeachment, o Ministério é dissolvido e a Secretaria das Mulheres passa a se vincular, novamente, ao Ministério da Justiça ${ }^{9}$.

O caminho do movimento das mulheres e sua expressão na esfera do Estado no Brasil é desenhado por idas e vindas. Pitanguy (2007) afirma que neste campo "o retrocesso é sempre possível" (p.32). A criação de órgãos de atenção aos direitos da mulher dentro da estrutura do Estado demonstra, sem dúvida, que a gestão estatal democrática está interessada na articulação com a sociedade civil em prol da legitimidade e institucionalização das políticas públicas de gênero. No entanto, a sedimentação desta necessidade obedece à capacidade de negociação dos atores estratégicos dentro e fora do Estado responsáveis por um quadro de alianças, apoios, obstáculos e enfrentamento, próprios do ambiente político.

No que se refere a Brasil, observa-se que a proximidade destes órgãos com a Presidência da República lhes impõe uma posição dentro do centro da tomada de decisões, bem como, lhes dá maior visibilidade. Trata-se de responder aos compromissos assumidos internacionalmente de elevar as políticas públicas de gênero ao centro do poder, na dinâmica das disputas e alianças no âmbito do governo. Isto, com certeza, é produto da transformação da gestão estatal que ocorre no decorrer dos anos pós abertura democrática, mais interessada na qualidade das relações entre governo e sociedade e, por sua vez, relacionada à capacidade

\footnotetext{
6 Os anos 90 ficou conhecida como a década dos Planos de Direitos Humanos.

${ }^{7}$ Lei 10539/2002

${ }^{8}$ A liberdade orçamentária somente atingida em 2012

${ }^{9}$ Parte da Reforma Ministerial do Governo interino - Medida Provisória 726 de 12 de Maio de 2016.

CONPEDI LAW REVIEW | QUITO - EQUADOR | v. 4 | n. 2 | p. 37 - 55 | JUL - DEZ | 2018 


\section{CONFERÊNCIAS NACIONAIS DE POLÍTICAS PARA A MULHER E A \\ FORMULAĈ̃O DE DIRETRIZES PARA AS POLÍTICAS PÚBLICAS DE ENFRENTAMENTO À VIOLÊNCIA CONTRA A MULHER NO BRASIL: PARTICIPAÇÃO \\ E REPRESENTAÇÃO}

de estabelecer normas e programas que satisfaçam demandas sociais.

Passados os primeiros trinta anos da abertura democrática no país e, portanto, na mudança das relações dos governos com a sociedade civil, o desafio está em perceber até que ponto as estruturas propostas encontram-se consolidadas a fim de solucionar problemas próprios das diferenças de gênero tão demarcadas. A violência contra a mulher está no centro desta discussão. Responder a questões referentes à persistência deste comportamento em sociedades, como a brasileira, que apresentam legislações punitivas a este comportamento, faz parte do processo de entendimento da efetividade das políticas públicas neste sentido. A urgência em instituir mecanismos capazes de promover mudanças de comportamento, bem como, de empoderar as mulheres dentro da sociedade em que vivem, é o que deve mobilizar a gestão das políticas públicas.

\section{PROCESSO POLÍTICO DECISÓRIO: OS PLANOS NACIONAIS DE POLÍTICAS} PARA AS MULHERES

As políticas públicas com fulcro nos direitos humanos só surgem no Brasil a partir de 1996 com o advento do Programa Nacional de Direitos Humanos, o chamado PNDH1. A Conferência de Viena em 1993 em sua segunda parte, especificamente no item 20, insta os governos a adotar medidas imediatas e desenvolver políticas sólidas de direitos humanos, inclusive com promulgação de leis adequadas e criação de instituições nacionais destinadas para tanto. Este documento consagrou a ideia de que planos de direitos humanos devem pertencer ao rol de políticas públicas de um Estado. É neste contexto que o primeiro Programa Nacional de Direitos Humanos brasileiro surge no cenário nacional e internacional ${ }^{10}$.

Não que a matéria não tivesse sido tratada anteriormente no país. Em realidade a redemocratização política enfrentada em meados dos anos 80 do século XX desperta interesses comuns em grupos sensíveis ${ }^{11}$ à esta mobilização nacional. A articulação destes grupos com organizações internacionais resultou na elevação dos direitos humanos ao

\footnotetext{
${ }^{10}$ O Plano de Direitos Humanos do Brasil foi um dos primeiros a serem lançados após a Conferência de Viena (1993). Primeiro documento do tipo na América Latina e um dos primeiros no mundo, a exemplo de Austrália, África do Sul e Filipinas.

${ }^{11}$ Sérgio Adorno em seu artigo "História e Desventura: 30. Programa Nacional de Direitos Humanos" (2010) esclarece que : "grupos tradicionalmente sensíveis à mobilização política - como profissionais liberais, jornalistas, professores universitários, estudantes, lideranças sindicais -, ainda que motivados por distintas orientações político-ideológicas, foram progressivamente articulando suas lutas com as organizações internacionais de direitos humanos." (p.8)
}

CONPEDI LAW REVIEW | QUITO - EQUADOR | v. 4 | n. 2 | p. 37 - 55 | JUL - DEZ | 2018 
patamar das garantias constitucionais. Os governos que se seguiram iniciam a tarefa de inserir os direitos humanos em suas políticas, visto a necessidade de cumprimento do comando constitucional de universalizar direitos. Mas foi apenas a partir de 1995, com o governo Fernando Henrique Cardoso, que o tema entrou definitivamente para a agenda nacional impulsionado pelo contexto internacional de debates sobre os direitos humanos.

A inserção de planos de direitos humanos no Brasil não têm a característica de políticas de gabinete, fechadas em discussões internas de governo. Assumindo a forma de políticas de Estado, estes documentos surgem no cenário brasileiro precedidos de amplos debates, inclusive com a sociedade civil. Neste diapasão, o Programa Nacional de Direitos Humanos (1) foi precedido da I Conferência Nacional de Direitos Humanos que se propôs a reunir organizações da sociedade civil brasileira para articular a defesa e promoção de direitos humanos no país. O resultado desta parceria entre governo e sociedade civil resultou em diretrizes para o texto final da $1^{\text {a }}$. Política de direitos humanos do país. A partir de então as conferências nacionais ${ }^{12}$ passaram a ser o ponto de reavaliação das políticas de direitos humanos no país.

Ao proceder a análise do plano fica claro que, de início, a intenção é enfrentar a desarticulação das várias instâncias decisórias do aparato de Estado e de governos bem como entre estes e a sociedade civil. A tarefa inicial, provocada por um contexto interno de banalização da violência ${ }^{13}$, foi a proteção dos direitos civis, fortemente representados pelo direito à vida, à integridade física, à liberdade e à igualdade perante a lei. Dessa forma, o texto foi sistematizado com 6 objetivos, 200 ações programáticas divididas entre realizáveis a curto, médio e longo prazo que traduzem em critérios determinados para tornar eficazes as medidas propostas dentro de um parâmetro de tempo.

Apesar de priorizar os princípios definidos pelo Pacto Internacional dos Direitos Civis e Políticos, o largo elenco de medidas demonstra uma predisposição para também proteger os direitos sociais, econômicos e culturais, visto que prevê ações para a implementação de políticas sociais contempladas em várias convenções internacionais como crianças, mulheres e trabalhadores. No item Mulheres, destaca o apoio ao Programa Nacional

\footnotetext{
${ }^{12}$ Entre 1996 e 2004 as Conferências Nacionais de Direitos Humanos ocorreram anualmente. A partir de 2004 de dois em dois anos. Isto porque a IX Conferência que ocorreu em 2004 instituiu o caráter deliberativo das suas recomendações.

${ }^{13} \mathrm{O}$ texto introdutório do PNDH1 reflete o ambiente de banalização da violência naquele momento no país: "Os assassinatos, as chacinas, o extermínio, os sequestros, o crime organizado, o tráfico de drogas e as mortes no trânsito não podem ser consideradas normais, especialmente em um Estado e em uma sociedade que se desejam modernos e democráticos." (1996,p.4)
} 


\section{CONFERÊNCIAS NACIONAIS DE POLÍTICAS PARA A MULHER E A \\ FORMULAĈ̃O DE DIRETRIZES PARA AS POLÍTICAS PÚBLICAS DE ENFRENTAMENTO À VIOLÊNCIA CONTRA A MULHER NO BRASIL: PARTICIPAĈ̃O \\ E REPRESENTAÇÃO}

de Combate à Violência contra a Mulher do governo federal, em curto prazo, além de incentivar a pesquisa e a divulgação de informações sobre violência e discriminação contra a mulher. A médio prazo, apresenta a promessa de reformular as normas de combate à violência e discriminação contra as mulheres.

Depois da criação da Secretaria Nacional dos Direitos Humanos e de realizadas 4 edições da Conferência Nacional dos Direitos Humanos, em 2002 é realizada a segunda edição do plano nacional, o chamado Programa Nacional de Direitos Humanos (2). Como era esperado, essa segunda edição revisa quais foram as políticas públicas que de fato se tornaram práticas rotineiras no país na promoção dos direitos humanos, reiterou os passos que desafiaram o implemento do Programa Nacional de Direitos Humanos (1) ao longo dos anos e estabeleceu um enfoque especial aos direitos sociais, econômicos e culturais.

Também apresentou uma metodologia nova a seu texto que passa a não mais ser descrito com ações propostas a curto, médio e longo prazos. A ideia era que, a partir da segunda edição, o plano passasse a ser implementado por programas de ações anuais definidoras das medidas a serem adotadas, acompanhadas dos recursos orçamentários destinados a financiá-lo e dos órgãos responsáveis por sua execução. Portanto, além de apresentar 6 objetivos e 518 proposições, aponta em seu anexo II, o correlacionamento das propostas com os programas governamentais de cada ministério, com o Plano Plurianual 2000-2003 e com a lei orçamentária anual de 2002. No que se refere às políticas para a mulher, o Programa Nacional de Direitos Humanos (2) confere maior ênfase à violência intrafamiliar, de assistência à mulher violentada e o fortalecimento de serviços de atendimento profissional ao homem agressor.

Em 2009, como fruto da maturidade institucional e dos avanços legislativos, além de 11 edições da Conferência Nacional dos Direitos Humanos, ocorre a publicação do Programa Nacional de Direitos Humanos (3). Este documento apresenta a noção de desenvolvimento como sendo aquele que permite a maior promoção possível de valores relacionados aos direitos humanos (eixo 2). Além disto, reafirma a universalização dos direitos humanos em contextos de desigualdades como sendo a possibilidade de exercer as diferenças sem exploração (eixo 3). No campo das relações com a sociedade, o texto do Programa Nacional de Direitos Humanos (3) consagra definitivamente o elo da sociedade civil e Estado na execução das políticas através da identificação de parcerias.

O destaque da $3^{\mathrm{a}}$. edição do Plano foi a transversalidade do tema e a interministerialidade impostas no cumprimento dos seus objetivos. Organizado em 6 eixos CONPEDI LAW REVIEW | QUITO - EQUADOR | v. 4 | n. 2 | p. 37 - 55 | JUL - DEZ | 2018 
orientadores, 25 diretrizes, 82 objetivos estratégicos e 521 ações programáticas que destacam os órgãos responsáveis pela execução bem como as parcerias, o PNDH3 tem uma melhor sistematização e uma linguagem mais direta com claras recomendações ao poder legislativo federal nas medidas que dependem de aprovação de leis e também aos outros entes federativos.

No que se refere à políticas que envolvem a mulher, o eixo 4 intitulado Segurança Pública, Acesso à Justiça e Combate à violência em sua diretriz 13 e, por sua vez, em seu objetivo V dispõe como meta a redução da violência motivada por diferenças de gênero e no objetivo VI, o enfrentamento do tráfico de pessoas. Já a diretriz 14 estabelece ações para combate à violência institucional no sistema penitenciário dando especial atenção a mulheres grávidas.

Entre a publicação do Programa Nacional de Direitos Humanos (2) e o Programa Nacional de Direitos Humanos (3) ocorre a rearticulação institucional do órgão responsável pelas políticas relativas à mulher no país. No último ano de governo do presidente Fernando Henrique Cardoso a criação da Secretaria dos Direitos da Mulher pela Lei 10539/2002 eleva as discussões sobre implementação das políticas para as mulheres a nível ministerial. Seguese a isto a instituição pelo governo Lula da Secretaria Especial de Políticas para as Mulheres como órgão executor de políticas e da rearticulação do Conselho dos Direitos da Mulher como órgão consultivo. O ano de 2003 também foi marcado por dois grandes passos no que se refere à violência contra as mulheres no Brasil. O primeiro deles foi a promulgação da Lei 10714 que instituiu a linha telefônica nacional de atendimento às mulheres vítimas de violência e o segundo foi a Lei 10778 que estabeleceu a notificação compulsória dos casos de violência contra as mulheres pelos profissionais da saúde pública aos órgãos municipais e estaduais a fim de possibilitar as autoridades responsáveis o acesso aos casos.

Em 2004, ano nacional da mulher, o $1^{\text {o. }}$ Plano Nacional de Políticas para a Mulher foi lançado e, nos moldes dos Programas Nacionais de Direitos Humanos, foi precedida de consulta à sociedade sistematizada através da $1^{\text {a }}$. Conferência Nacional de Políticas para a Mulher $^{14}$. Sistematizado em quatro eixos temáticos, sendo o último deles dedicado ao enfrentamento da violência contra a mulher, este plano apresenta a mesma preocupação, já

\footnotetext{
${ }^{14}$ Segundo o Centro Feminista de Estudos e Assessoria (CFEMEA): O processo que culminou com a Conferência Nacional contou com a realização de mais de 2000 plenárias estaduais e municipais. Durante todas as atividades, os movimentos de mulheres e feminista estiveram presentes tentando construir, em conjunto, os sentidos das diretrizes para um Plano Nacional. A $1^{\text {a }}$ Conferência Nacional de Políticas para as Mulheres reuniu cerca de 2.500 pessoas em Brasília entre os dias 15 e 17 de julho de 2004. Disponível em: http://www.cfemea.org.br/index.php?option=com content \&view=article\&id=997:1 -conferencia-nacional-depoliticas-para-as-mulheres\&catid=120:numero-136-agosto-de-2004\&Itemid=129.
}

CONPEDI LAW REVIEW | QUITO - EQUADOR | v. 4 | n. 2 | p. 37 - 55 | JUL - DEZ | 2018 


\section{CONFERÊNCIAS NACIONAIS DE POLÍTICAS PARA A MULHER E A FORMULAĈ̃O DE DIRETRIZES PARA AS POLÍTICAS PÚBLICAS DE ENFRENTAMENTO À VIOLÊNCIA CONTRA A MULHER NO BRASIL: PARTICIPAÇÃO E REPRESENTAÇÃO}

exposta nos planos nacionais de direitos humanos, de transversalidade e intersetorialidade ${ }^{15}$ da igualdade de gêneros. Assim, o maior objetivo deste eixo temático era priorizar uma política mais pontual sobre a violência que abrangesse o aumento da rede de atendimento da mulher vítima de violência e da sua organização conjunta, a capacitação dos profissionais envolvidos nesta rede de atendimento, a produção de informações sobre a violência e, ainda, a ampliação do acesso à justiça e à assistência jurídica gratuita.

O plano que tinha duração temporal de três anos, pois já nasceu com a obrigatoriedade de revisão em 2007, ano da II Conferência Nacional de Políticas para a Mulher, se destaca pela preocupação com a organização dos mecanismos de implementação e monitoramento. A intenção é viabilizar um sistema de informações que mantenha o próprio governo e a sociedade informados sobre o andamento das ações governamentais em prol da implementação das ações propostas com análise das dificuldades encontradas. Para tanto, ao instituir o Comitê de Articulação e Monitoramento, além de coordenar os órgãos setoriais incumbidos de fornecer as informações necessárias, ainda cria um comitê técnico para de posse das informações recebidas, subsidiar a elaboração dos relatórios de gestão.

O ano de 2007, um ano depois da promulgação da Lei Maria da Penha e um antes da segunda edição do Plano Nacional de Políticas para a Mulher, é marcado por dois importantes documentos que compõem o arcabouço das políticas públicas de violência contra as mulheres. O Pacto pelo Enfrentamento da Violência contra a Mulher, que representou o envolvimento das instâncias de governo no plano nacional, e o Plano Nacional de Enfrentamento do Tráfico de Pessoas, que cuidou de uma forma específica da violência contra as mulheres, traduziram a amplitude do comprometimento do Estado com a questão.

O Pacto foi lançado pelo governo federal como parte de sua Agenda Social de Aceleração do Desenvolvimento ${ }^{16} \mathrm{e}$, além da transversalidade e intersetorialidade presentes nos planos nacionais, inclui a noção de capilaridade ${ }^{17}$, essencial para políticas implementadas

\footnotetext{
${ }^{15}$ Transversalidade e Intersetorialidade são termos que se relacionam no modo de fazer políticas públicas. De acordo com a ONUMULHERES: "Em linhas gerais, a missão institucional desses mecanismos de gênero pode ser descrita como: formulação de políticas públicas para o cumprimento dos acordos internacionais, a transversalização de gênero por meio de acordos intersetoriais, a formulação e execução de planos e programas para a promoção da igualdade entre homens e mulheres e o desenvolvimento de mecanismos de monitoramento das políticas existentes. Na abordagem intersetorial, as políticas públicas desenvolvidas e/ou coordenadas pelos mecanismos de gênero devem contemplar áreas de educação e prevenção, segurança, justiça, saúde, habitação, trabalho e participação política. A formulação de políticas para a violência baseada em gênero é prioridade em cada mecanismo de gênero, com a criação de setores especializados nesta temática, direcionados para a implementação das leis especiais vigentes em cada país.” (Relatório Regional, Julho de 2011, p. 29)

${ }^{16}$ Programa de Aceleração do Crescimento lançado em 2007 (PAC).

${ }^{17}$ Segundo ONUMULHERES: "Uma estratégia comum e que tem permitido aos mecanismos de gênero dos

CONPEDI LAW REVIEW | QUITO - EQUADOR | v. 4 | n. 2 | p. 37 - 55 | JUL - DEZ | 2018
} 
em países de sistema federativo. Formado por cinco eixos que traduziram a necessidade de garantia e aplicabilidade à Lei Maria da Penha; a ampliação e fortalecimento da rede de serviços; a garantia de segurança cidadã e acesso à justiça; a garantia dos direitos sexuais e reprodutivos com o enfrentamento da exploração sexual e do tráfico de mulheres e, por fim, a garantia da autonomia das mulheres em situação de violência e ampliação de seus direitos. A grande contribuição deste documento para o combate à violência contra as mulheres foi a reunião de um amplo conjunto de ministérios, secretarias especiais e outras instituições públicas aportando recursos humanos e financeiros para o intuito.

Pela primeira vez uma política de combate à violência contra a mulher no país conferiu de forma objetiva competências e responsabilidades às unidades federativas, estados e municípios, além da União. A divisão de responsabilidade responderam à lógica das atribuições constitucionais de cada ente federativo. Assim coube à União as ações relacionadas às campanhas nacionais, à central de atendimento à mulher, aos seminários e capacitação nacional. Aos estados, a criação e reaparelhamento de serviços de segurança pública e do judiciário. Aos municípios, a criação e reaparelhamento de serviços de assistência social, além das campanhas locais.

Os estados foram o ente federativo escolhido para organização primária da capilaridade e deveriam se associar à União comprometendo-se a realizar parcerias com os municípios para a implementação de serviços. O modelo escolhido para o pacto entre as unidades federativas tem por meta dar visibilidade ao problema e instrumentalizar o planejamento das ações. Para tanto, o pacto instituiu seis passos a serem preenchidos: a criação do organismo local de políticas para as mulheres; a elaboração pelos estados de um projeto integral básico que deverá conter um diagnóstico local da violência e a definição dos denominados municípios-polos ${ }^{18}$ com as ações a serem executadas atendendo aos eixos prioritários; a assinatura do acordo de cooperação federativa; a constituição das câmaras técnicas estaduais e municipais que realizarão a gestão e o monitoramento do pacto; a

governos nacionais/federais ampliar sua atuação, conquistar fortalecimento político, e aumentar sua capacidade em promover mudanças concretas na vida das mulheres, tem sido a capilarização das políticas de gênero através da criação (ou incentivo para que sejam criados) de mecanismos de gênero nos governos locais e também das chamadas "área-mulher" nos ministérios e secretarias do Poder Executivo. Em alguns países, esta experiência de criação de áreas especializadas tem sido reproduzida também no poder Legislativo e poder Judiciário". (Relatório Regional, Julho de 2011, p. 30)

${ }^{18}$ Segundo IPEA: "Dado o grande número de municípios existentes no país, a escassez de recursos de toda ordem e a desnecessidade - ou inviabilidade - de que todos os serviços sejam ofertados em todos os municípios brasileiros, o pacto tem trabalhado com a ideia de município-polo. Os municípios-polo são definidos como as regiões administrativas do estado que já constituem referência na região, destacando-se por: $i$ ) exercer influência sobre o entorno; $i$ ) ser um centro regional; iii) ser referência na oferta de serviços; e $i v$ ) ser dotado de capacidade de gestão e articulação." (Boletim de Políticas Sociais no. 21, 2013, p. 520)

CONPEDI LAW REVIEW | QUITO - EQUADOR | v. 4 | n. 2 | p. 37 - 55 | JUL - DEZ | 2018 


\section{CONFERÊNCIAS NACIONAIS DE POLÍTICAS PARA A MULHER E A \\ FORMULAĈ̃O DE DIRETRIZES PARA AS POLÍTICAS PÚBLICAS DE ENFRENTAMENTO À VIOLÊNCIA CONTRA A MULHER NO BRASIL: PARTICIPAÇÃO \\ E REPRESENTAÇÃO}

aprovação das propostas nestas câmaras com encaminhamento para a câmara técnica federal, e, finalmente o credenciamento no portal de convênios.

Já o Plano Nacional de Enfrentamento do Tráfico de Pessoas, embora não seja uma política específica para mulheres, pretendeu responder ao Protocolo de Palermo ${ }^{19} \mathrm{e}$, portanto, leva em consideração o movimento de pessoas, o uso de engano e coerção e, ainda, a finalidade de exploração que pode assumir diferentes formas. A política inclui as dimensões da atenção às vítimas, prevenção, repressão e responsabilização e inclui as mesmas metas do PNPM, quais sejam, ampliação da rede de atendimento e capacitação dos agentes.

Seguindo-se a isto ocorre em 2008 o II Plano Nacional de Políticas para a Mulher que em um processo de construção e aperfeiçoamento estabelece, no eixo temático em questão, como objetivo primordial a consolidação da política nacional de enfrentamento à violência contra a mulher com plena efetivação da Lei Maria da Penha. Dessa forma, pretende reduzir os índices de violência contra as mulheres, fortalecer e humanizar a rede de atendimento, intervir no comportamento social a fim de desconstruir estereótipos e promover mudança cultural e, inaugurando a preocupação com a violência institucional, dar especial atenção aos direitos humanos das mulheres presidiárias.

É também a partir desta edição que a noção de enfrentamento à violência ${ }^{20}$ se amplia sem se restringir apenas à questão do combate, mas atingindo também as dimensões da prevenção, assistência e garantia de direitos. A ideia é enfrentar todas as formas de violência contra as mulheres a partir de uma perspectiva de gênero e de uma visão integral deste fenômeno. No entanto, a inovação do plano está na ampliação do sistema nacional de informação com a consolidação do Observatório da Lei Maria da Penha, a fim de possibilitar maior controle social da implementação das políticas. A proposta é que a partir disto seja possível produzir e analisar indicadores sociais, políticas públicas, legislação e poder legislativo além do comportamento dos veículos de comunicação e mídia.

Com finalização em 2011, somente foi sucedido pelo III Plano Nacional de Políticas para a Mulher em 2013, dada a reestruturação institucional que atingiu a Secretaria Especial

\footnotetext{
${ }^{19}$ Protocolo Relativo à Prevenção, Repressão e Punição do Tráfico de Pessoas, em Especial Mulheres e Crianças que foi aprovado pela resolução da Assembleia-Geral no 55/25. O protocolo entrou em vigor em 25 de dezembro de 2003 e foi o primeiro instrumento global juridicamente vinculante com uma definição consensual sobre o tráfico de pessoas.

${ }^{20}$ Com a realização da I e da II Conferência Nacional de Políticas para Mulheres (I e II CNPM) e com a construção coletiva de dois Planos Nacionais de Políticas para Mulheres, o Enfrentamento à Violência contra as Mulheres é consolidado como um eixo intersetorial e prioritário no campo das políticas para as mulheres. (BRASIL, 2011,p.16)
}

CONPEDI LAW REVIEW | QUITO - EQUADOR | v. 4 | n. 2 | p. 37 - 55 | JUL - DEZ | 2018 
de Políticas para a Mulher com o advento da Lei 12314/2012 que a elevou ao status de Ministério com a junção da Secretaria de Políticas de Promoção da Igualdade Racial. A terceira edição surge sem muitas inovações apresentando questões mais pontuais como o caso da violência obstétrica ou mais abrangentes como o enfrentamento do tráfico de mulheres que no mesmo ano foi também contemplado pela segunda edição do Plano Nacional de Enfrentamento ao Tráfico de Pessoas (II PNETP) ${ }^{21}$. Outro destaque, levando em consideração o quesito transversalidade, foi o advento da Lei 13239/2015 que instituiu a possiblidade de cirurgia plástica corretora pelo Sistema Único de Saúde para as mulheres vítimas de violência.

Há ainda que se destacar a Política Nacional de Atenção às Mulheres encarceradas lançada em 16 de janeiro de 2014 a fim de atender às Regras de Bangkok ${ }^{22}$. A política conta com 6 (seis) metas prioritárias que incluem a sistematização de um banco de dados para as penitenciárias do país; o respeito aos direitos fundamentais das presas a fim de atender à perspectiva de gênero; a estrutura física adequada capaz de atender a várias demandas, principalmente, a da maternidade; o foco na melhoria da segurança e da gestão prisional; a capacitação dos agentes prisionais; e o cuidado com as egressas.

\section{AS CONFERÊNCIAS NACIONAIS DE POLÍTICAS PARA A MULHER: PARTICIPAÇÃO COMO REPRESENTAÇÃO}

Como afirma Pogrebinschi (2010: 10), as conferências nacionais no país têm, como primeiro sentido, caráter deliberativo, visto serem produto de "processos intercomunicativos de formação de opinião e da vontade ocorridos na esfera pública”. Afirma a autora ainda que há também o caráter normativo do documento final das conferências, vez que o processo político de agregação de preferências perpassa pelo debate e aprovação por voto.

Esses perfis deliberativos e normativos vão de encontro à leitura que Habermas (2012) propõe da noção de democracia deliberativa como sendo o movimento comunicativo em que se dá a decisão política. Assim, ao analisar a realização democrática procedimental, este autor afirma que a decisão política deve ser tomada por meio da discussão e não pela ordem. Sua análise de democracia deliberativa contém, portanto, uma revalorização da esfera política. Para ele, é por meio da esfera pública que os cidadãos enxergam a possibilidade de crítica ao Estado e de entendimento entre as várias propostas políticas que surgem na sociedade.

\footnotetext{
${ }^{21}$ Preocupado com ações para implementação de rede de atendimento no exterior e nas fronteiras.

22 Regras das Nações Unidas para o tratamento de mulheres presas e medidas não privativas de liberdade para mulheres infratoras.
} 


\section{CONFERÊNCIAS NACIONAIS DE POLÍTICAS PARA A MULHER E A FORMULAĈ̃O DE DIRETRIZES PARA AS POLÍTICAS PÚBLICAS DE ENFRENTAMENTO À VIOLÊNCIA CONTRA A MULHER NO BRASIL: PARTICIPAÇÃO \\ E REPRESENTAÇÃO}

Para Habermas, há, portanto, um poder comunicativo oriundo da sociedade civil que pode dar certos direcionamentos ao processo de exercício político. A fim de poder exercer uma pressão real sobre o sistema político, a esfera pública faz uso da encenação e da intensificação de seus argumentos. Este é o papel desempenhado pelos movimentos sociais, pelas iniciativas cidadãs, fóruns cidadãos e as associações políticas que na interpretação habermasiana representam os agrupamentos da sociedade civil de perspectiva progressista. São eles que percebem os problemas e os potencializam de forma que comovam as pessoas com diferentes tipos de interesses, organizam a opinião pública e sensibilizam o sistema político.

Frazer (2013) acresce a este debate a posibilidade de superação das injustiças de primeira ordem relacionadas à má distribuição, ao falso reconhecimento e à falsa representação política comum. Esta autora entende o político como o palco em que as lutas por distribuição e reconhecimento são conduzidas. Portanto, a dimensão política revela não apenas quem pode fazer reinvindicações por distribuição e reconhecimento, mas também como tais reinvindicações devem ser introduzidas no debate e julgadas. Tendo em vista esta concepção é que Fraser afirma que a característica política da injustiça é a falsa representação e essa ocorre quando fronteiras políticas e/ou regras decisórias funcionam de modo a negar a algumas pessoas a possiblidade de participar como um par, com os demais, na interação social.

Há que se reconhecer que as conferências nacionais ao serem produto de uma convocação de instâncias governamentais de inclusão, como é o caso do Conselho Nacional de Direitos da Mulher, fazem do percurso da participação (antecedidas por análises locais) ${ }^{23}$ uma espécie de "trampolim" para a superação da falsa representação. Isto porque a deliberação, produto de amplos debates, retornam a estas instâncias a fim de compor as agendas e implementação de políticas públicas a serem executadas administrativamente ou mesmo para influenciar as proposições no Congresso Nacional.

É desse modo que as plenárias constituídas localmente (Conferências Municipais) e as constituídas regionalmente (Conferências Estaduais), depois de devidamente convocadas pelo Conselho Nacional de Políticas para a Mulher, reuniram o maior número possível de

\footnotetext{
${ }^{23}$ Com mais de 2.500 participantes, destes 1.800 delegadas credenciadas, a I CNPM aconteceu após a realização de mais de 2 mil plenárias estaduais e municipais, que envolveu cerca de 130 mil pessoas. A II CNPM conseguiu ampliar o número para 2.800 na etapa nacional. Já a III CNPM diminuiu propositalmente o número de participantes na nacional para 2.125 delegadas, mas manteve a ampliação local, envolvendo mãos de 200 mil mulheres no processo.. (SILVA, 2014: 33)
}

CONPEDI LAW REVIEW | QUITO - EQUADOR | v. 4 | n. 2 | p. 37 - 55 | JUL - DEZ | 2018 
representantes da sociedade civil para elaborar uma lista de prioridades a serem discutidas a nível nacional (Conferência Nacional) divididas em 5 eixos temáticos, a saber: enfrentamento à pobreza, geração de renda, trabalho, acesso ao crédito e a terra; saúde da mulher, direitos reprodutivos e sexuais; violência de gênero e políticas de segurança; poder, democracia e participação; e educação, cultura e produção de conhecimento. (SILVA, 2014: 52 )

O resultado deste processo de consulta e deliberação foi a formulação de um documento final capaz de propor a inclusão da pauta das mulheres em políticas setoriais e gerais ou mesmo de ampliar o rol de políticas específicas. Este documento final subsidiaria, então, a redação dos Planos Nacionais de Políticas para a Mulher elaborados pela Secretaria de Políticas para a Mulher, órgão até então, diretamente ligado à Presidência da República. Dessa forma, o movimento final de consulta às instâncias micro (municipais), média (estaduais) e macro (nacional), uma vez convocadas pelos órgãos superiores, têm o condão de a eles retornarem com propostas consolidadas por um intenso debate. É por essa razão que Pogrebinschi (2012:9) afirma que "as conferências nacionais têm a potencialidade de fazer de problemas locais soluções nacionais".

O fato de congregar as preferências locais e regionais sobre temas que envolvem a mulher, as conferências nacionais são um espaço de participação política para além da arena eleitoral que se traduzem na representação de interesses em prol da mulher. Essa participação representativa alcança objetivos concretos no momento em que a deliberação final alcança os burocratas e políticos eleitos pelo voto popular e insta que estes a converta em leis e políticas. Trata-se, portanto, de incluir na pauta governamental interesses edificados na esfera pública e para além disto, de legitimar a participação de um grupo na criação e implementação de políticas públicas em prol de si mesmo.

Tanto assim o é que o texto de apresentação do I Plano Nacional de Políticas para a Mulher afirma ser ele resultado da mobilização de "cerca de 120 mil mulheres que participaram diretamente dos debates e apresentaram as propostas para elaboração do Plano Nacional de Políticas para as Mulheres"(BRASIL, 2006) . E o mesmo ocorre com o II Plano Nacional de Políticas para a Mulher que afirma na sua apresentação ser "resultado da mobilização de quase 200 mil brasileiras que participaram, em todo país, das Conferências Municipais e Estaduais e elegeram 2.700 delegadas à II Conferência Nacional de Políticas para Mulheres." (BRASIL, 2013)

Em última análise, pode-se afirmar que as Conferências Nacionais de Políticas para a Mulher tiveram a pretensão de colocar a mulher no centro do processo político-decisório, 


\section{CONFERÊNCIAS NACIONAIS DE POLÍTICAS PARA A MULHER E A \\ FORMULAC ÃO DE DIRETRIZES PARA AS POLÍTICAS PÚBLICAS DE ENFRENTAMENTO À VIOLÊNCIA CONTRA A MULHER NO BRASIL: PARTICIPAÇÃO \\ E REPRESENTAÇÃO}

alargando, assim, os seus canais de participação nos governos democráticos. Ao possibilitar a participação de um grupo socialmente minoritário na resolução de problemas públicos que o envolve, a representação deste grupo se faz cada vez mais presente na esfera pública. De forma que além das representações político-partidárias que se consolidam através do voto popular, a mulher alcança o patamar de empoderamento de sua cidadania, ao se ver representada em políticas que convergem com as demandas levantadas pelas conferências nacionais.

\section{CONSIDERAÇÕES FINAIS}

A Constituição brasileira, proclamada como Constituição Cidadã, incorporou alguns mecanismos de democracia direta e participativa como alternativa à democracia representativa. Este é o caso específico do plebiscito, referendo e iniciativa popular (artigo 14). Mas para além destes três casos específicos, a Constituição de 1988 ainda estipulou a participação social como forma de gestão pública, (artigos 10, 187 e 231), além do princípio da descentralização administrativa com gestão participativa estar presente em alguns direitos sociais, como ocorre na saúde (artigo 198) e na educação (artigo 206).

Avançando, portanto na proposta constitucional, o Brasil ao instituir políticas públicas de direitos humanos o fez precedendo-as de um debate amplo dentro do país. A forma pela qual este processo se deu foi através de conferências, espaço cedido à sociedade civil para debater e propor as necessidades e aspirações dos diferentes setores da população. A organização destas conferências perpassam por etapas locais, regionais e a última que congrega as deliberações das primeiras é a Conferência Nacional. A fim de legitimar as ações políticas e a gestão pública das deliberações das conferências a serem transformadas em diretrizes de políticas públicas surgem os conselhos que também se organizam em nível local, regional e nacional.

As políticas públicas de enfrentamento à violência contra a mulher, pauta constante dos Planos Nacionais de Direitos da Mulher, também foram edificadas realizando este percurso de participação e representação. Acresce-se a isto o fato da Secretaria de Políticas para a Mulher e o Conselho Nacional de Políticas para a Mulher, órgãos responsáveis pela execução e implementação das políticas públicas, se posicionarem dentro da estrutura máxima do poder executivo federal e a partir deste patamar impulsionarem a realização da Conferência Nacional bem como articularem seus resultados. 
Este movimento entre sociedade civil e governo encontra guarida na teoria argumentativa de Habermas (2012), visto que para uma democracia deliberativa a esfera pública deve ser utilizada pelos mais diversos grupos para discussão e sensibilização do sistema político a fim de que suas demandas sejam atendidas. Além disto, este modelo de participação através de Conferências supera a ideia de falsa representação proposta por Frazer (2013), vez que estrutura regras com o fim de incluir no debate social grupos historicamente excluídos da esfera pública, possibilitando, dessa forma, a superação de barreiras políticas entre os diversos grupos sociais. E é a partir destas colocações que a ideia de representação política através da participação em conferências, no modelo estabelecido no país, se apresenta como uma forma que acresce à tradicional representação político- partidária.

Para a consolidação da democracia necessário se faz que a participação cidadã se dê de forma eficaz. Os gregos resolviam este problema através das reuniões em praça pública, embora possa ser discutível a ideia de cidadania da época. Depois, já com a aspiração de cortes de privilégios no Estado aristocrático, a lei passou a expressar a vontade geral e para isso o parlamento passou a ser visto como a representação dos ideais democráticos. Embora o avanço do tempo tenha inserido nesta representação todo o tipo de reinvindicações, aquelas que vão desde às aspirações burguesas e capitalistas às dos trabalhadores e assalariados, o mesmo modelo perpetua até os dias atuais. A representação político-partidária, no entanto, pode promover desequilíbrios de participação, vez que seu exercício pode privilegiar grupos sociais em detrimento de outros.

Para que esses desequilíbrios possam ser sanados necessário se faz dimensionar a ideia de representação política. As Conferências Nacionais brasileiras com o intuito de construir diretrizes e ações administrativas que vinculem as políticas públicas de inclusão e no modelo agregador do debate local e regional atingem este fim. A democracia se expande e a representação popular toma novos contornos a partir da participação, mais visível, da sociedade civil na política. É neste sentido que participação e representação, portanto, parecem caminhar juntas.

\section{REFERÊNCIAS}

BRASIL. Decreto 5390 de 08 de março de 2005. Aprova o Plano Nacional de Políticas para as Mulheres - PNPM, institui o Comitê de Articulação e Monitoramento e dá outras providências. Diário Oficial da República do Brasil, Brasília, 9 de março de 2005, Seção 1, p. 1. 


\section{CONFERÊNCIAS NACIONAIS DE POLÍTICAS PARA A MULHER E A \\ FORMULAĈ̃O DE DIRETRIZES PARA AS POLÍTICAS PÚBLICAS DE ENFRENTAMENTO À VIOLÊNCIA CONTRA A MULHER NO BRASIL: PARTICIPAÇÃO \\ E REPRESENTAÇÃO}

Decreto 6347 de 8 de janeiro de 2008. Aprova o Plano Nacional de Enfrentamento ao Tráfico de Pessoas - PNETP e institui Grupo Assessor de Avaliação e Disseminação do referido Plano. Diário Oficial da República do Brasil, Brasília, 9 de janeiro de 2008, Seção 1 ,p. 1.

Decreto 6387 de 05 de março de 2008. Aprova o II Plano Nacional de Políticas para as Mulheres - II PNPM, e dá outras providências. Diário Oficial da República do Brasil, Brasília, 06 de março de 2008, Seção 1, p. 1.

Decreto 6347 de 8 de janeiro de 2008. Aprova o Plano Nacional de Enfrentamento ao Tráfico de Pessoas - PNETP e institui Grupo Assessor de Avaliação e Disseminação do referido Plano. Diário Oficial da República do Brasil, Brasília, 9 de janeiro de 2008, Seção 1 ,p. 1.

Decreto 7901 de 4 de fevereiro de 2013. Institui a Coordenação Tripartite da Política Nacional de Enfrentamento ao Tráfico de Pessoas e o Comitê Nacional de Enfrentamento ao Tráfico de Pessoas - CONATRAP. Diário Oficial da República do Brasil, Brasília, 5 de fevereiro de 2013, Seção 1, p. 4.

Decreto 7959 de 13 de março de 2013. Dispõe sobre o Plano Nacional de Políticas para as Mulheres, para o período de 2013 a 2015, altera o Decreto $\mathrm{n}^{\circ}$ 5.390, de 8 de março de 2005, e dá outras providências. Diário Oficial da República do Brasil, Brasília, 14 de março de 2013, Seção 1, p.2.

Decreto 8086 de 30 de agosto de 2013. Institui o Programa Mulher: Viver sem Violência e dá outras providências. Diário Oficial da República do Brasil, Brasília, 30 de agosto de 2013, Seção 1 - Edição Extra, p. 1.

Lei 11340 de 07 de agosto de 2006. Cria mecanismos para coibir a violência doméstica e familiar contra a mulher, nos termos do $\S 8^{\circ}$ do art. 226 da Constituição Federal, da Convenção sobre a Eliminação de Todas as Formas de Discriminação contra as Mulheres e da Convenção Interamericana para Prevenir, Punir e Erradicar a Violência contra a Mulher; dispõe sobre a criação dos Juizados de Violência Doméstica e Familiar contra a Mulher; altera o Código de Processo Penal, o Código Penal e a Lei de Execução Penal; e dá outras providências. Diário Oficial da República do Brasil, Brasília, 8 de agosto de 2006, Seção 1 , p. 1.

Ministério da Justiça. Secretaria de Assuntos Legislativos. Pensando o Direito: igualdade de direitos entre homens e mulheres. Brasília, n. 11, 2009.

Ministério da Justiça. Secretaria de Assuntos Legislativos. Pensando o Direito: Conferências Nacionais, Participação Social e Processo Legislativo. Brasília, n.27, 2010.

Ministério da Justiça. Secretaria de Assuntos Legislativos. Pensando o Direito: violência contra a mulher e as práticas institucionais. Brasília, n.52, 2015.

BRASIL. ONU Mulheres. O progresso das mulheres no Brasil (2003-2010). Rio de Janeiro: CEPIA, 2011. 
Presidência da República. Secretaria de Políticas para as Mulheres. Rede de enfrentamento à violência contra as mulheres. Coleção Enfrentamento à violência contra as mulheres. Brasília, 2011.

CAMPOS, Carmen Hein (org.). Lei Maria da Penha comentada em uma perspectiva jurídico-feminista. Rio de Janeiro: Editora Lumen Juris, 2011.

FRASER. Nancy. Rethinking the public sphere: A contribution to the critique of actually existing democracy. Social Text n.25/26, 1990, p.56-80. Disponível em http://www.apas.be/dpt/apt/3564/rethinking_the_public_sphere. Acesso em 06/08/2014.

Repensando o reconhecimento. Enfoques- Revista dos alunos do programa de pósgraduação em Sociologia e Antropologia da UFRJ. Rio de Janeiro. V.09,N.01, Ago-2010, p.114-128. Disponível em http://www.enfoques.ifcs.ufrj.br. Acesso em 06/08/2014.

Reconhecimento sem ética?. Lua Nova. São Paulo. N.70, 2007, p. 101-138. Disponível em http://www.scielo.br/pdf/n70/a06n70.pdf. Acesso em 06/08/2014.

Reenquadrando a Justiça em um mundo globalizado. Lua Nova. São Paulo. N.77, 2009, p.11-39. Disponível em http://www.scielo.br/pdf/n77/a01n77.pdf. Acesso em $06 / 08 / 2014$.

Justiça Anormal. Revista da Faculdade de Direito da Universidade de São Paulo, v.108, jan/dez 2013, p.739-768. Disponível em http://www.revistas.usp.br/ rfdusp/article/view/680001. Acesso em 06/08/2014.

GARGARELLA, Roberto; PÁDUA, Thiago; GUEDES, Jefferson. Constitucionalismo latino-americano: direitos sociais e a "sala de máquinas" da Constituição. Universitas Jus, V.27, n.2, p.33-41, 2016.

HABBERMAS, Jurguen. Direito e Democracia: entre facticidade e validade. Tradução Flávio Beno Siebeneichler. V.I. 2ª ed. Rio de Janeiro: Tempo Brasileiro, 2012.

Direito e Democracia: entre facticidade e validade. Tradução Flávio Beno Siebeneichler. V.II. Rio de Janeiro: Tempo Brasileiro, 2012.

La Inclusión del Otro: Estudios de Teoría Política. Traducción Juan Carlos Velasco Arroyo y Gerard Villar Roca. Barcelona: Paidós Ibérica, 2010.

MONTAÑO, Sonia; PITANGUY, Jacqueline; LOBO, Thereza. As políticas públicas de gênero: um modelo pra armar. O caso do Brasil. Santiago de Chile: Naciones Unidas, 2003. (mujer y desarollo, 45).

NASCIMENTO, Luana Regina Ferreira do. Aplicação da Lei Maria da Penha: um estudo sobre estereótipos de gênero no Judiciário. 2012. Dissertação (Mestrado em Serviço Social) - Instituto de Ciências Humanas, Departamento de Serviço Social, Universidade de Brasília, Brasília. 


\section{CONFERÊNCIAS NACIONAIS DE POLÍTICAS PARA A MULHER E A FORMULAÇÃO DE DIRETRIZES PARA AS POLÍTICAS PÚBLICAS DE ENFRENTAMENTO À VIOLÊNCIA CONTRA A MULHER NO BRASIL: PARTICIPACÃO \\ E REPRESENTAÇÃO}

PIMENTA, Fabrícia Faleiros. Políticas feministas e os feminismos na política: o Conselho Nacional dos Direitos da Mulher (1985-2005). 2010. Tese (Doutorado em História) Instituto de Ciências Humanas, Departamento de História, Universidade de Brasília, Brasília.

POGREBINSCHI, Thamy. Conferências Nacionais e Políticas Públicas para grupos minoritários. Texto para discussão. Rio de Janeiro: Instituto de Pesquisa Econômica Aplicada, 2012.

SILVA, Maria Camila Florêncio da. As conferências Nacionais de Política para as Mulheres e os Sentidos Atribuídos à Deliberação. 2014. Dissertação (Mestrado em Direito) - Escola de Direito de São Paulo da Fundação Getulio Vargas, FGV, São Paulo. 